03

\title{
Изменение нормальной спектральной излучательной способности при плавлении элементов
}

\author{
(ㄱ Д.В. Косенков, В.В. Сагадеев \\ Казанский национальный исследовательский технологический университет, \\ 420015 Казань, Татарстан, Россия \\ e-mail: Dmi-kosenkov@yandex.ru
}

Поступило в Редакцию 7 июля 2021 г.

В окончательной редакции 20 сентября 2021 г.

Принято к публикации 1 декабря 2021 г.

Проведены экспериментальное и расчетное исследования нормальной спектральной излучательной способности при плавлении различных металлов, даны схема установки и методика проведения опытов. Дана оценка возможностей электромагнитной теории для описания зависимости поведения нормальной спектральной излучательной способности металлов и полуметаллов.

Ключевые слова: нормальная спектральная излучательная способность, длина волны, металл, электромагнитная теория.

DOI: 10.21883/JTF.2022.03.52129.207-21

\section{Введение}

В научной литературе имеется ограниченное количество опытных данных по нормальным спектральным степеням черноты жидких и твердых чистых веществ. Знание этих параметров необходимо для количественных и качественных расчетов теплообмена в высоконагруженном теплообменном оборудовании. Поэтому актуальность этой научной проблематики остается весьма высокой.

В настоящее время в публикациях различных авторов [1-5] рассмотрена как методика проведения спектральных измерений нормальной излучательной способности чистых металлов, так и непосредственно сами экспериментальные данные в широком температурном диапазоне, включая фазовый переход твердое тело-жидкость.

Ранее считалось (работы $[6,7])$, что монох роматические степени черноты металлов вблизи видимой области спектра при переходе из твердого состояния в жидкое не изменяются.

Авторы работы [8] на основе измерений спектральных степеней черноты при длине волны $0.65 \mu \mathrm{m}$ жидких тугоплавких металлов - молибдена, ниобия, ванадия и титана - отмечали, что нельзя сделать однозначный вывод о том, как изменяется и изменяется ли вообще монохроматическая излучательная способность при плавлении.

Автор монографии [9] делает вывод, что вблизи точки плавления различных металлов в диапазоне длин волн от 0.4 до $2 \mu \mathrm{m}$ отсутствует скачкообразное изменение нормальной спектральной излучательной способности. Численный рост степеней черноты металлов в жидком состоянии по сравнению с твердым сопоставим с изменением удельного электрического сопротивления при тех же значениях температуры. В другой монографии этого же автора [10] рекомендуются спектральные степени черноты 24 металлов, рассчитанных по формуле Хагена-Рубенса [9], которая не содержит произвольных констант и позволяет определить спектральную излучательную способность как функцию проводимости.

Последние исследования в этой области [11-13] показывают изменение с уменьшением спектральной нормальной излучательной способности ряда металлов (титан, ванадий, молибден) от длины волны и согласие с полуэмпирической оценкой, основанной на модели Друде [14].

Целью настоящей работы является экспериментальное исследование нормальной спектральной излучательной способности ряда металлов в области температур плавления в твердом и жидком состоянии с проведением анализа полученных результатов.

\section{1. Описание эксперимента}

Авторами настоящей работы произведено исследование нормальной спектральной излучательной способности свинца, олова, цинка, кадмия, висмута и сурьмы на экспериментальном стенде (рис. 1) с измененной оснасткой внутрикратерного пространства измерительной ячейки. В отличие от ячейки, представленной в [15], применялся радиометр со встроенным сменным узкополосным фильтром. Узкополосные инфракрасные дисперсионные фильтры изготовлены Центральным конструкторским бюро с опытным производством института физики АН Республики Беларусь (табл. 1).

В работе измерялось отношение нормальных спектральных степеней черноты расплава и полированного металла (полуметалла) при температуре опыта, включая точку плавления: $\varphi_{\lambda}=\varepsilon_{\lambda, \text { liquid }} / \varepsilon_{\lambda, \text { solid }}$ - где $\varepsilon_{\lambda, \text { liquid }}$, 


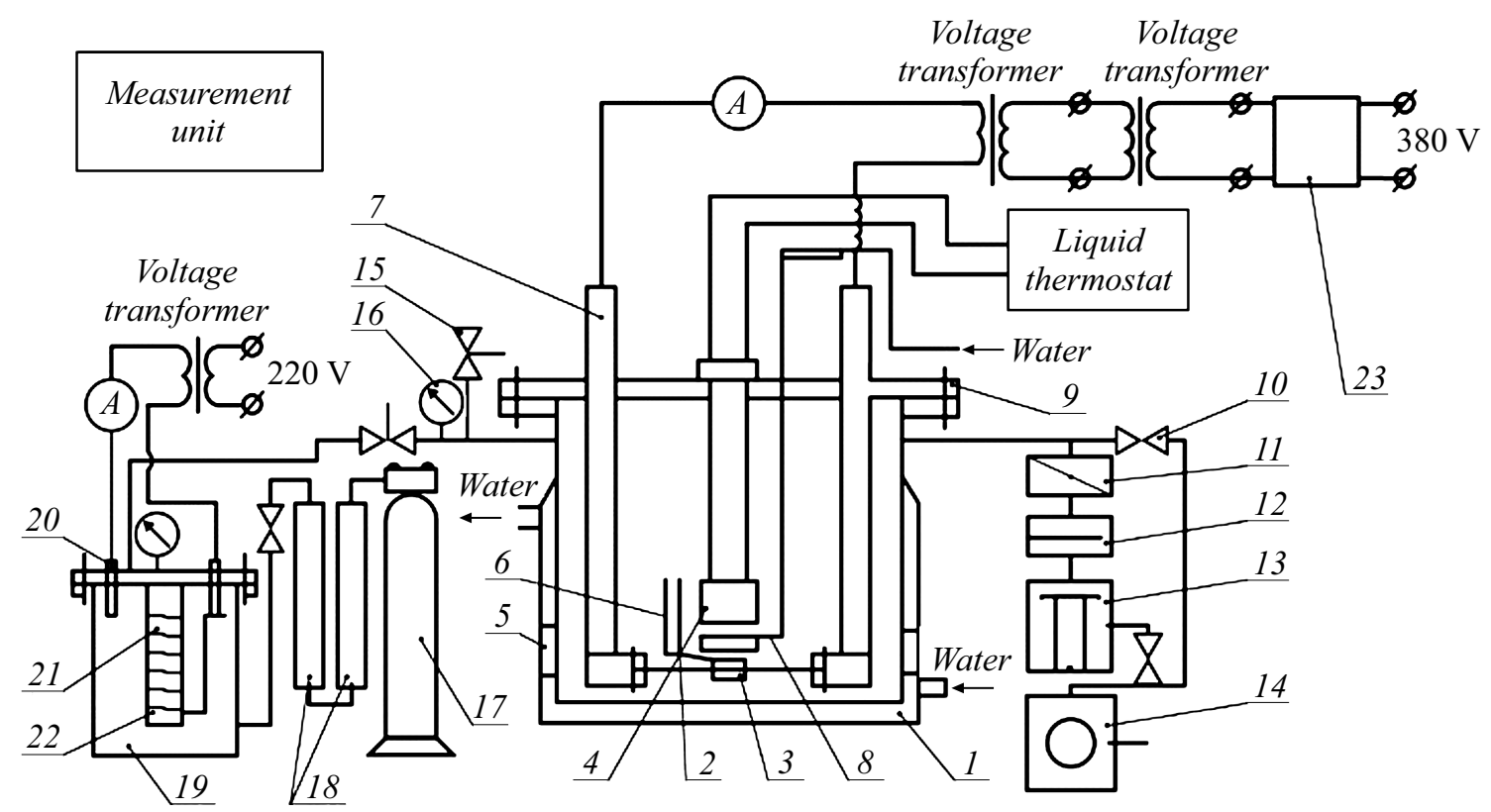

Рис. 1. Схема экспериментального стенда: 1 - корпус, 2 - лента-нагреватель, 3 - исследуемый металл, 4 - радиометр с встроенным сменным узкополосным фильтром, 5 - окно, 6 - термопары, 7 - охлаждаемые токовводы, 8 - водоохлаждаемая заслонка, 9 - крышка, 10 - вентили, 11 - затвор, 12 - ловушка, 13 - насос диффузионный, 14 - насос форвакуумный, 15 - система натекателей, 16 - вакуумметр, 17 - баллон с инертным газом (аргон), 18 - механические фильтры, $19-$ объем подготовки газа, 20 - водоохлаждаемые токовводы, 21 - фарфоровая труба, 22 - вольфрамовая спираль, 23 - стабилизаторы напряжения.

Таблица 1. Спектральные характеристики узкополосных фильтров

\begin{tabular}{c|c|c|c|c|c|c}
\hline № фильтра & 1 & 2 & 3 & 4 & 5 & 6 \\
\hline $\begin{array}{c}\text { Полоса пропускания } \\
\text { фильтра, } \mu \mathrm{m}\end{array}$ & 0.69 & 1.63 & 1.97 & 4.2 & 7.3 & 10.6
\end{tabular}

$\varepsilon_{\lambda, \text { solid }}$ - это нормальная спектральная степень черноты металла (полуметалла) соответственно в жидкой и твердой фазах.

Исследования проведены при длинах волн $(\lambda)$ от 0.69 до $10.6 \mu \mathrm{m}$. Выбранный диапазон длин волн находится за красной границей фотоэффекта и он не может влиять на полученные результаты эксперимента. Фильтр в каждом экспериментальном замере устанавливался в радиометре между термоэлементом и термостатируемыми диафрагмами.

В экспериментальных исследованиях применялся абсолютный радиационный метод. Экспериментальный стенд вакууммировался до $10^{-2} \mathrm{~Pa}$ и в последствии заполнялся специально осушенным и отожженным инертным газом - аргоном, до давления $10^{5} \mathrm{~Pa}$. Термостат поддерживал постоянную температуру радиометра с узкополосным фильтром равной $293 \pm 0.1 \mathrm{~K}$. Охлаждающая жидкость - дистиллированная вода, подавалась как в рубашку рабочей камеры, так и в полости токовводов, к которым крепились модель абсолютно черного тела или лента резистивного нагревателя с исследуемым веществом. Все экспериментальные замеры проводились при достижении стационарного режима. Нулевое значение термоЭДС приемника излучения говорило о его качественном термостатировании и готовности к работе. Радиометр со встроенным узкополосным фильтром градуировался по съемной цилиндрической формы модели абсолютно черного тела (АЧТ) при достижении равенства температур „донышка“ модели и стенок.

Максимальные температуры металлов в опытах ограничивались скоростью испарения жидкого металла или его температурой кипения. Состояние поверхности металлического зеркала контролировалось визуально, в течение всего эксперимента. Поверхность расплава считалась оптически гладкой. При кристаллизации поверхность, как правило, получалась шероховатой с углублением в виде небольшого кратера в центре. Эти спектральные степени черноты образца с такой поверхностью оказывались завышенными. Поэтому поверхность застывшего образца, снятого с нагревателя, шлифовалась и полировалась до зеркального состояния с оценкой качества поверхности металла профилометром.

По существующей методике ГОСТ Р 8.736-2011 авторами произведена оценка погрешности эксперимента, состоящей из систематической и случайной ошибок. Максимальная относительная погрешность составляла $\pm 2 \%$. С учетом градуировки применяемой образцовой платина-родиевой термопары максимальная погреш- 
Таблица 2. Экспериментальные величины

\begin{tabular}{c|c|c|c|c|c|c}
\hline \multirow{2}{*}{$\begin{array}{c}\text { Полоса } \\
\text { пропускания, } \\
\mu \mathrm{m}\end{array}$} & \multicolumn{3}{|c}{ Отношение нормальных спектральных излучательных способностей $\varphi_{\lambda n \epsilon} T_{\text {melting }}, \mathrm{K}$} \\
\cline { 2 - 7 } & $\begin{array}{c}\text { Свинец } \\
600\end{array}$ & $\begin{array}{c}\text { Олово } \\
505\end{array}$ & $\begin{array}{c}\text { Цинк } \\
693\end{array}$ & $\begin{array}{c}\text { Кадмий } \\
594\end{array}$ & $\begin{array}{c}\text { Висмут } \\
544\end{array}$ & $\begin{array}{c}\text { Сурьма } \\
903\end{array}$ \\
\hline 0.69 & 1.02 & 1.03 & 1.02 & 1.01 & 0.99 & 0.99 \\
1.63 & 1.03 & 1.04 & 1.07 & 1.03 & 0.99 & 0.99 \\
1.97 & 1.04 & 1.05 & 1.12 & 1.07 & 0.98 & 0.97 \\
4.2 & 1.10 & 1.06 & 1.26 & 1.15 & 0.97 & 0.96 \\
7.3 & 1.44 & 1.38 & 1.93 & 1.57 & 0.97 & 0.81 \\
10.6 & 1.64 & 1.48 & 2.39 & 1.95 & &
\end{tabular}

ность опыта была оценена от 5 до $8 \%$ в зависимости от температуры.

\section{2. Результаты исследований}

Полученные экспериментальные значения отношения $\varphi_{\lambda}-$ нормальной спектральной излучательной способности металлов в жидком состоянии к такому же в твердом состоянии вблизи температур плавления представлены в табл. 2.

Для исследуемых металлов в области $0.69 \mu \mathrm{m}$ спектра $\varphi_{\lambda}$ близка к единице (рис. 2), т.е. металл или полуметалл излучают одинаково, влияния фазового перехода не зафиксировано. Этот результат согласуется с имеющимися измерениями в видимой области спектра (от 0.4 до $0.7 \mu \mathrm{m}$ ) $[9,10]$. С ростом длины волны зафиксировано, что величина $\varphi_{\lambda}$ начинает отклоняться от единицы, достаточно резко уходя вверх для металлов и вниз для полуметаллов.

Наибольшие изменения значений $\varphi_{\lambda}$ наблюдюется для цинка (в 2.4 раза) и кадмия (в 1.95 раз). Эти же металлы при плавлении имеют наибольшее увеличение интегральной нормальной полусферической степени черноты.

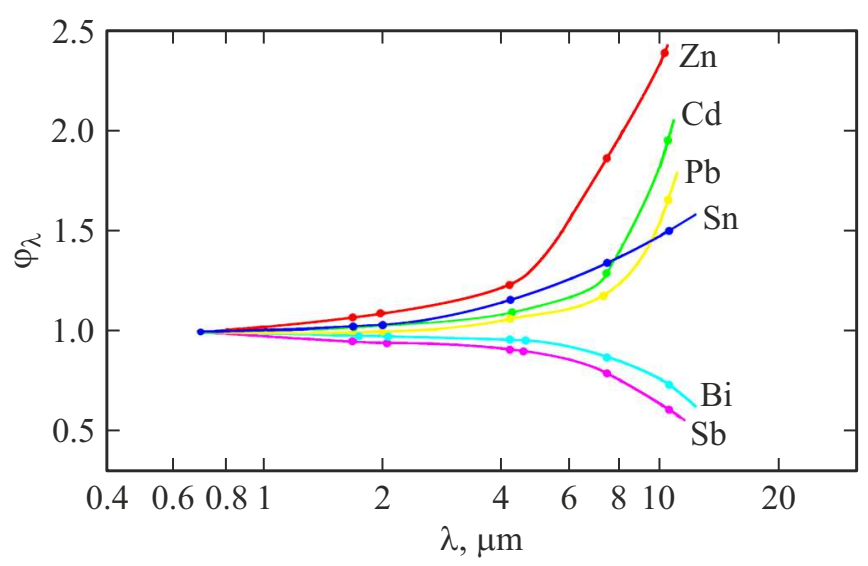

Рис. 2. Величина $\varphi_{\lambda}$ для цинка, кадмия, олова, свинца, сурьмы и висмута - область плавления элементов.

\section{3. Теоретические подходы}

Рассмотрим возможность применения электромагнитной теории для расчета изменения спектральной степени черноты при плавлении шести исследованных элеменTOB.

В соответствии с формулой Друде, считая ее справедливой и для жидкой фазы, имеем

$$
\begin{gathered}
\varphi_{\lambda 1}=\frac{\varepsilon_{\lambda, \text { liquid }}}{\varepsilon_{\lambda, \text { solid }}}=\sqrt{\frac{\rho_{\text {liquid }}}{\rho_{\text {solid }}}}, \\
\varphi_{\lambda 2}=\frac{\varepsilon_{\lambda, \text { liquid }}}{\varepsilon_{\lambda, \text { solid }}}=\sqrt{\frac{\rho_{\text {liquid }}}{\rho_{\text {solid }}}} \\
\times \frac{1-0.188 \sqrt{\rho_{\text {liquid }} / \lambda}+0.0249 \rho_{\text {liquid }} / \lambda}{1-0.188 \sqrt{\rho_{\text {solid }} / \lambda}+0.0249 \rho_{\text {solid }} / \lambda}, \\
\varphi_{\lambda 3}=\frac{\varepsilon_{\lambda, \text { liquid }}}{\varepsilon_{\lambda, \text { solid }}}=\sqrt{\frac{\rho_{\text {liquid }}}{\rho_{\text {solid }}}} \\
1-0.184 \sqrt{\rho_{\text {liquid }} / \lambda}+0.0329 \rho_{\text {liquid }} / \lambda-2 \pi c \tau \\
\times \frac{\times\left(0.5 / \lambda-0.184 \sqrt{\rho_{\text {liquid }} / \lambda^{1.5}}+0.049 \rho_{\text {liquid }} / \lambda^{2}\right)}{1-0.184 \sqrt{\rho_{\text {solid }} / \lambda}+0.0329 \rho_{\text {solid }} / \lambda-2 \pi c \tau}, \\
\times\left(0.5 / \lambda-0.184 \sqrt{\rho_{\text {solid }} / \lambda^{1.5}}+0.049 \rho_{\text {solid }} / \lambda^{2}\right)
\end{gathered}
$$

где $\rho_{\text {solid }}, \rho_{\text {liquid }}-$ удельное электрическое сопротивление металла при температуре опыта в твердой и жидкой фазах соответственно; $c$ - скорость света; $\tau$ время релаксации электрона; $\varphi_{\lambda 1}, \varphi_{\lambda 2}, \varphi_{\lambda 3}-$ отношение нормальной спектральной излучательной способности металлов в жидком состоянии к такому же в твердом состоянии вблизи температур плавления, рассчитанное по $[14,16,17]$ соответственно.

Удельное электрическое сопротивление у металлов и полуметаллов имеет сильную зависимость от температуры $[18,19]$. При температурах фазового перехода наблюдается скачек изменения параметра $\rho$. Так, к примеру, в жидком олове [20] вблизи температуры 793 K наблюдаются скачкообразное изменение термоЭДС и излом зависимости электрического сопротивления от температуры (рис. 3).

Соотношение (1) дает не зависящий от длины волны скачок степеней черноты. Точно такие же величины 


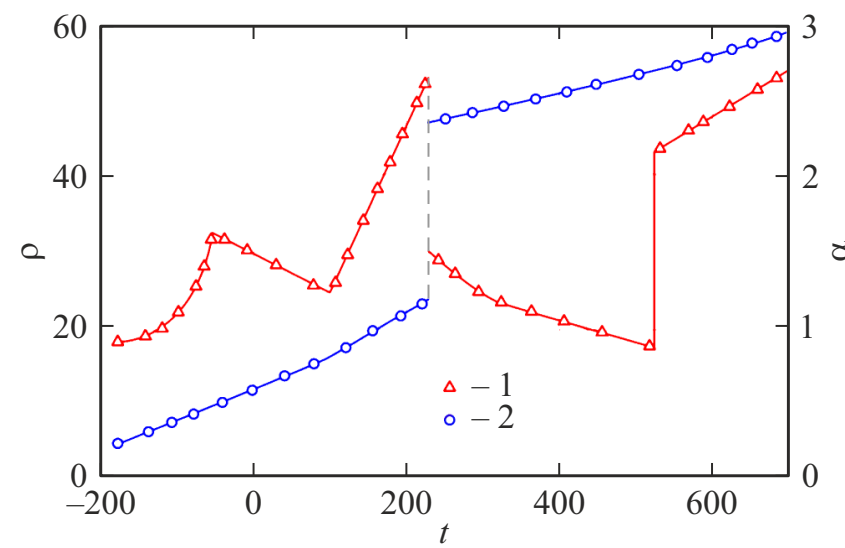

Рис. 3. Электрическое сопротивление и термоЭДС олова [20]: $1-\alpha, \mu \mathrm{V} / \mathrm{K}, 2-\rho, \mu \Omega \cdot \mathrm{cm}$.

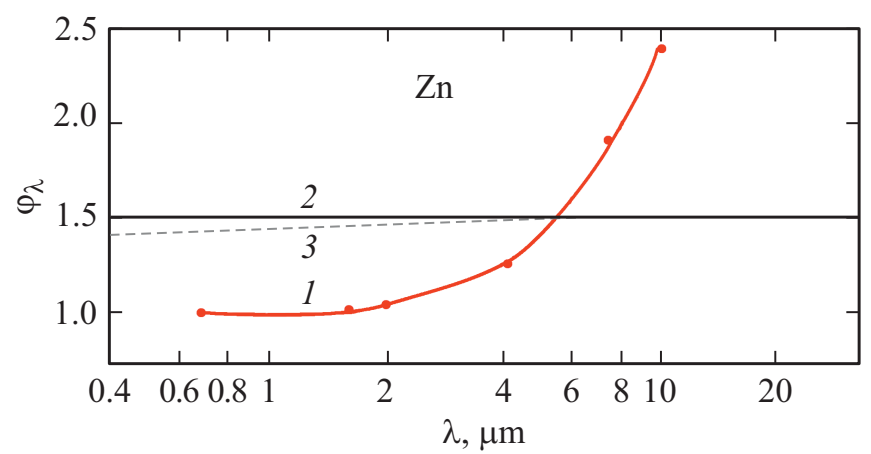

Рис. 4. Величины $\varphi_{\lambda}$ для цинка: 1 - измерения авторов, $2-$ расчеты по формуле (1), 3 - расчеты по формулам (2) и (3).

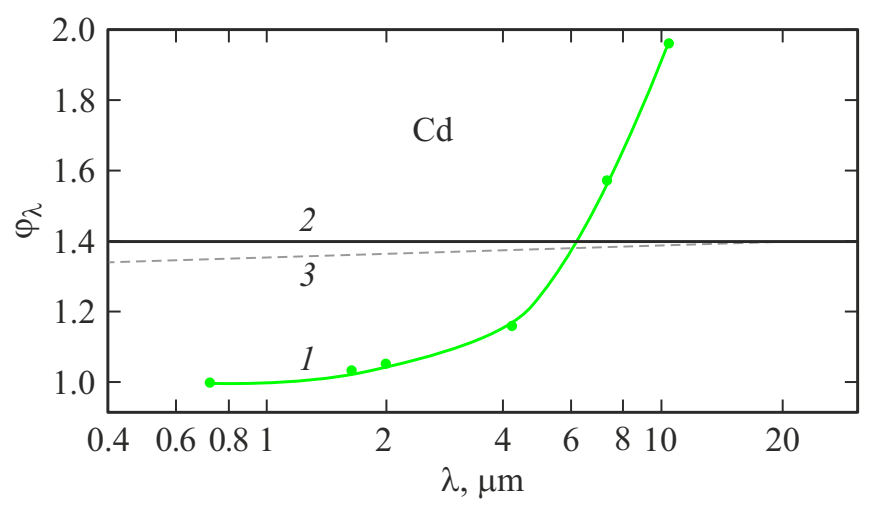

Рис. 5. Величины $\varphi_{\lambda}$ для кадмия: 1 - измерения авторов, $2-$ расчеты по формуле (1), 3 - расчеты по формулам (2) и (3).

скачка получаются по формуле Друде и для интегральных степеней черноты. Два других соотношения (2) и (3) содержат первый множитель, равный выражению (1). Вторым множителем в них являются дроби, численные значения которых близки к единице.

На рис. 4-7 показаны изменения спектральных нормальных степеней черноты в зависимости от длины волны и скачки интегральных степеней черноты при плавлении цинка, кадмия, олова, свинца сурьмы и висмута. На этих же графиках представлены величины $\varphi_{\lambda 1}, \varphi_{\lambda 2}$ и $\varphi_{\lambda 3}$, рассчитанные по формулам (1)-(3). Для сравнения проведена линия $\varphi$, соответствующая отношению экспериментальных интегральных степеней черноты твердой и жидкой фаз. Расчеты по соотношениям (1)-(3), основанным на формулах Друде, ХагенаРубенса и усовершенствованному соотношению ХагенаРубенса, для изменения спектральной степени черноты при плавлении дают близкие величины (табл. 3). Значения $\varphi_{\lambda 2}$ и $\varphi_{\lambda 3}$ по формулам (2) и (3) различаются между собой менее чем на $1 \%$, поэтому на графиках они изображены одной линией.

Анализ рис. 3-6 показывает, что электромагнитная теория не только количественно, но и качественно не воспроизводит спектральный ход изменения степени черноты при плавлении. В коротковолновой части спектра до длин волн 2-3 $\mu$ m скачек степени черноты

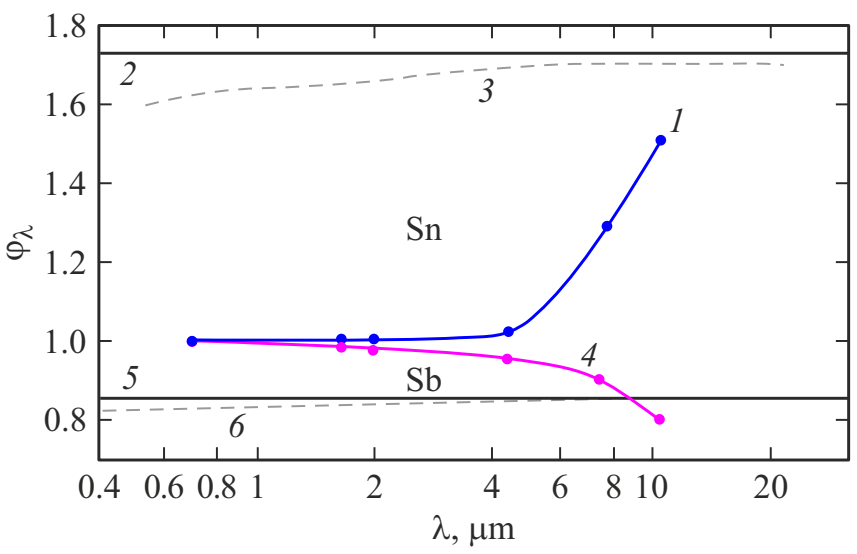

Рис. 6. Величины $\varphi_{\lambda}$ для олова: 1 - измерения авторов, 2 - расчеты по формуле (1), 3 - расчеты по формулам (2) и (3), для сурьмы: 4 - измерения авторов, 5 - расчеты по формуле (1), 6 - расчеты по формулам (2) и (3).

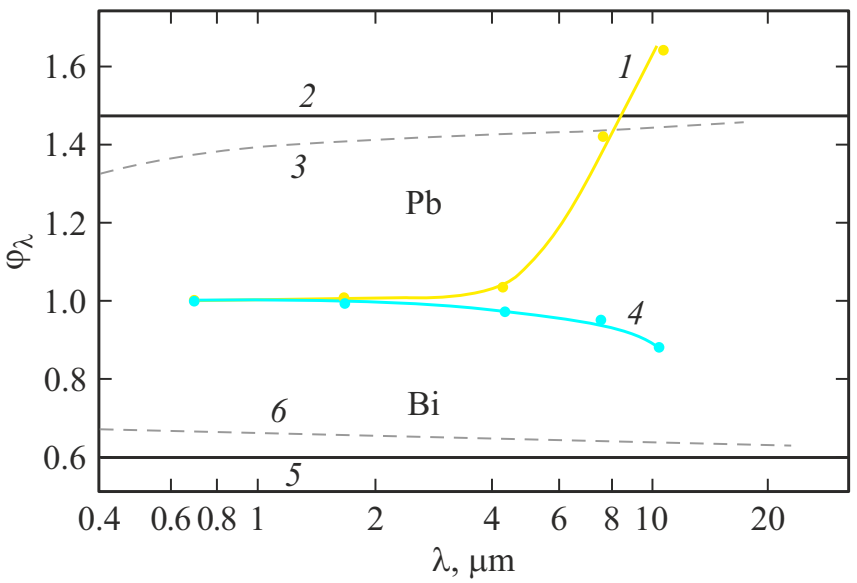

Рис. 7. Величины $\varphi_{\lambda}$ для свинца: $1-$ измерения авторов, 2 - расчеты по формуле (1), 3 - расчеты по формулам (2) и (3); для висмута: 4 - измерения авторов, 5 - расчеты по формуле (1), 6 - расчеты по формулам (2) и (3). 
Таблица 3. Величины $\varphi_{\lambda 1}, \varphi_{\lambda 2}$ и $\varphi_{\lambda 3}$, найденные по формулам (1)-(3)

\begin{tabular}{|c|c|c|c|c|c|c|}
\hline$\lambda, \mu \mathrm{m}$ & $\varphi_{\lambda 1}$ & $\varphi_{\lambda 2}$ & $\varphi_{\lambda 3}$ & $\varphi_{\lambda 1}$ & $\varphi_{\lambda 2}$ & $\varphi_{\lambda 3}$ \\
\hline & \multicolumn{3}{|c|}{ Олово } & \multicolumn{3}{|c|}{ Сурьма } \\
\hline 0.65 & 1.732 & 1.628 & 1.636 & 0.851 & 0.878 & 0.875 \\
\hline 1 & 1.732 & 1.646 & 1.631 & 0.851 & 0.874 & 0.870 \\
\hline 2 & 1.732 & 1.669 & 1.653 & 0.851 & 0.868 & 0.865 \\
\hline 4 & 1.732 & 1.690 & 1.688 & 0.851 & 0.863 & 0.860 \\
\hline 10 & 1.732 & 1.703 & 1.698 & 0.851 & 0.859 & 0.858 \\
\hline 15 & 1.732 & 1.708 & 1.705 & 0.851 & 0.857 & 0.856 \\
\hline \multirow[t]{2}{*}{20} & 1.732 & 1.711 & 1.712 & 0.851 & 0.856 & 0.853 \\
\hline & \multicolumn{3}{|c|}{ Цинк } & \multicolumn{3}{|c|}{ Висмут } \\
\hline 0.65 & 1.512 & 1.446 & 1.440 & 0.604 & 0.675 & 0.673 \\
\hline 1 & 1.512 & 1.457 & 1.456 & 0.604 & 0.668 & 0.662 \\
\hline 2 & 1.512 & 1.472 & 1.462 & 0.604 & 0.654 & 0.651 \\
\hline 4 & 1.512 & 1.483 & 1.466 & 0.604 & 0.641 & 0.643 \\
\hline 10 & 1.512 & 1.492 & 1.468 & 0.604 & 0.628 & 0.652 \\
\hline 15 & 1.512 & 1.496 & 1.470 & 0.604 & 0.624 & 0.620 \\
\hline \multirow[t]{2}{*}{20} & 1.512 & 1.498 & 1.475 & 0.604 & 0.621 & 0.619 \\
\hline & \multicolumn{3}{|c|}{ Свинец } & \multicolumn{3}{|c|}{ Кадмий } \\
\hline 0.65 & 1.460 & 1.369 & 1.364 & 1.400 & 1.353 & 1.349 \\
\hline 1 & 1.460 & 1.383 & 1.381 & 1.400 & 1.361 & 1.358 \\
\hline 2 & 1.460 & 1.403 & 1.401 & 1.400 & 1.372 & 1.369 \\
\hline 4 & 1.460 & 1.418 & 1.416 & 1.400 & 1.380 & 1.377 \\
\hline 10 & 1.460 & 1.433 & 1.431 & 1.400 & 1.387 & 1.386 \\
\hline 15 & 1.460 & 1.438 & 1.436 & 1.400 & 1.389 & 1.388 \\
\hline 20 & 1.460 & 1.441 & 1.440 & 1.400 & 1.391 & 1.399 \\
\hline
\end{tabular}

отсутствует, тогда как по электромагнитной теории для цинка, кадмия, олова и свинца он достигает 40-70\%, для сурьмы и висмута скачек отрицателен и равен $15 \%$ (сурьма) и 40\% (висмут). При больших длинах волн величины $\varphi_{\lambda 2}$ и $\varphi_{\lambda 3}$ практически становятся равными $\varphi_{\lambda 1}$ и не изменяются с длиной волны, тогда как экспериментальные значения $\varphi_{\lambda}$ растут (цинк, кадмий, олово и свинец) или уменьшаются (сурьма и висмут).

Исходя из опытных величин $\varphi_{\lambda}$, можно предположить

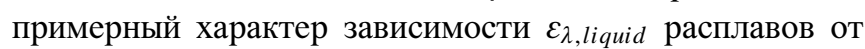
длины волны. В области коротких длин волн $\varepsilon_{\lambda \text {,liquid, }}$ как и для твердых металлов, примерно пропорциональ-

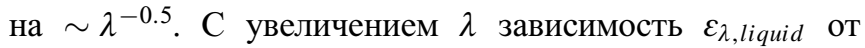
длины волны для жидких металлов ослабевает, величина $\varepsilon_{\lambda, \text { liquid }}$ может пройти через минимум и даже начать расти при больших $\lambda$.

У элементов, степень черноты которых при плавлении уменьшается, с увеличением $\lambda$ зависимость от длины волны будет усиливаться, степень черноты $\varepsilon_{\lambda}$, liquid будет падать более круто, чем в твердой фазе. В результате металлы и полуметаллы в жидкой фазе будут иметь качественно разную зависимость $\varepsilon_{\lambda \text {,liquid }}$ от длины волны.

\section{Выводы}

1. Экспериментально получены отношения нормальных спектральных излучательных способностей ряда металлов и полуметаллов абсолютным радиационным методом.

2. Установлен характер поведения отношения нормальных спектральных излучательных способностей свинца, олова, цинка, кадмия, висмута и сурьмы от длины волны.

3. Проведена оценка возможностей электромагнитной теории для описания зависимости поведения нормальной спектральной излучательной способности металлов и полуметаллов в точке фазового перехода. Показано, что рассмотренная теория в большинстве случаев не воспроизводит экспериментальные значения.

\section{Конфликт интересов}

Авторы заявляют, что у них нет конфликта интересов.

\section{Список литературы}

[1] H. Watanabe, M. Susa, K. Nagata. Metall. Mater. Transactions A, 28 (12), 2507 (1997). DOI: 10.1007/s11661-997-0008-7

[2] L.S. Dubrovinsky, S.K. Saxena. High Temperatures-high Pressures - HIGH TEMP-HIGH PRESS, 31 (4), 393 (1999). ISSN 0018-1544

[3] H. Watanabe, M. Susa, H. Fukuyama, K. Nagata. Intern. J. Thermophysics, 24, 473-488. DOI: $10.1023 / \mathrm{A}: 1022924105951$.

[4] H. Watanabe, M. Susa, Hiroyuki Fukuyama, K. Nagata. Intern. J. Thermophysics, 24, 1105 (2003). DOI: $10.1023 / \mathrm{A}: 1025013320127$

[5] T. Ishikawa, J. Okada, P.-F. Paradis, Y. Watanabe. J. Chem. Thermodynamics, 112 (6), 7 (2017). DOI: $10.1016 /$ j.jct.2017.04.006

[6] А.В. Соколов. Оптические свойства металлов и некоторых веществ (Физматлит, М., 1961), 464 с.

[7] Д.Я. Свет. Оптические методы измерения истинных температур (Наука, М., 1982), 296 с.

[8] И.Т. Иванов, В.Ф. Полоников. Исследование интегральной степени черноты цветных металлов в твердом и расплавленном состояниях в вакууме (Сб. науч. тр. Моск. ин-т инженер. железнодорож. тр-та, М., 1982), $102 \mathrm{c}$.

[9] М.А. Брамсон. Инфракрасное излучение нагретых тел (Наука, М., 1964), 223 с.

[10] М.А. Брамсон. Справочные таблицы по инфракрасному излучению нагретых тел (Наука, М., 1964), 310 с.

[11] T. Ishikawa, Ch. Koyama, Y. Nakata, Y. Watanabe, P.F. Paradis. J. Chem. Thermodynamics, 131, 557 (2019). DOI: $10.1016 /$ j.jct.2018.12.002

[12] A. Eber, P. Pichler, G. Pottlacher. Intern. J. Thermophysics, 42 (2), 17 (2021). DOI: 10.1007/s10765-020-02769-7

[13] T. Ishikawa, Ch. Koyama, Y. Nakata, Y. Watanabe, P.F. Paradis. J. Chem. Thermodynamics, 163, 106598 (2021). https://doi.org/10.1016/j.jct.2021.106598

[14] R. Siegel, J.R. Howell. Thermal Radiation Heat Transfer (Taylor \& Francis, NY., 2002) 
[15] Д.В. Косенков, В.В. Сагадеев. ЖТФ, 91 (12), 1909 (2021). DOI: 10.21883/JTF.2021.12.51755.103-21

[16] Излучательные свойства твердых металлов, справочник, под общ. ред. А.Е. Шейндлина (Энергия, М., 1974)

[17] К.М. Шварев. Известия вуз, сер. физика, 1, 7 (1978).

[18] Теплофизические свойства металлов при высоких температурах, справочник под ред. В.Е. Зиновьева (Металлургия, М., 1989)

[19] Кинетические свойства металлов при высоких темпеpaтурах, справочник под ред. В.Е. Зиновьева (Металлургия, М., 1984)

[20] А.М. Магомедов. ИФЖ, 37 (2), 336 (1979). 